Exacerbations were defined using our usual symptomatic criteria from daily diary cards (Seemungal et al, AJRCCM 1998).

Results 42 COPD patients had a mean \pm SD age of $72.7 \pm 8.7$ years, $64 \%$ male, $17 \%$ current smokers, median(IOR) 46 (19.71) pack years, mean \pm SD stable FEV1 $1.22 \pm 0.64 \mathrm{~L}$ and $50.7 \pm 21.5 \%$ predicted, BMI $27.7 \pm 7.4 \mathrm{~kg} / \mathrm{m} 2.13$ (31\%) patients had a diagnosis of GORD, of whom 12 (92\%) were taking regular acid suppression therapy. There was a median (IOR) interval of $141(80,233)$ days between the stable and exacerbation visits.

Although median (IOR) FSSG and HARO scores were higher at exacerbation compared to the stable state, this was not statistically significant due to high variability $(6.5(4.0,13.0)$ vs $5.0(1.5,11.5)$, $p=0.247$ and $15.5(9.0,23)$ vs $18.5 \quad(11.5,24.5), p=0.096$ respectively).

$16 / 42(38 \%)$ patients had a high FSSG score $(\geq 8)$ in the stable state compared with $20 / 42(48 \%)$ at exacerbation $(p=0.378) .10 / 42$ (24\%) changed from a low stable FSSG to a high score at exacerbation.

$27 / 42(64 \%)$ patients had a high HARQ score $(\geq 13)$ in the stable state compared with $30 / 42(71 \%)$ at exacerbation $(p=0.483) .7 / 42$ $(17 \%)$ changed from a low stable HARQ to a high score at exacerbation.

Conclusions GORD symptom scores are not significantly higher during acute COPD exacerbations. Due to high variability, approximately one fifth of COPD patients had a low GORD symptom score when stable and high scores at exacerbation implicating worsening reflux in some exacerbations. Further work is required to understand the potential mechanisms.
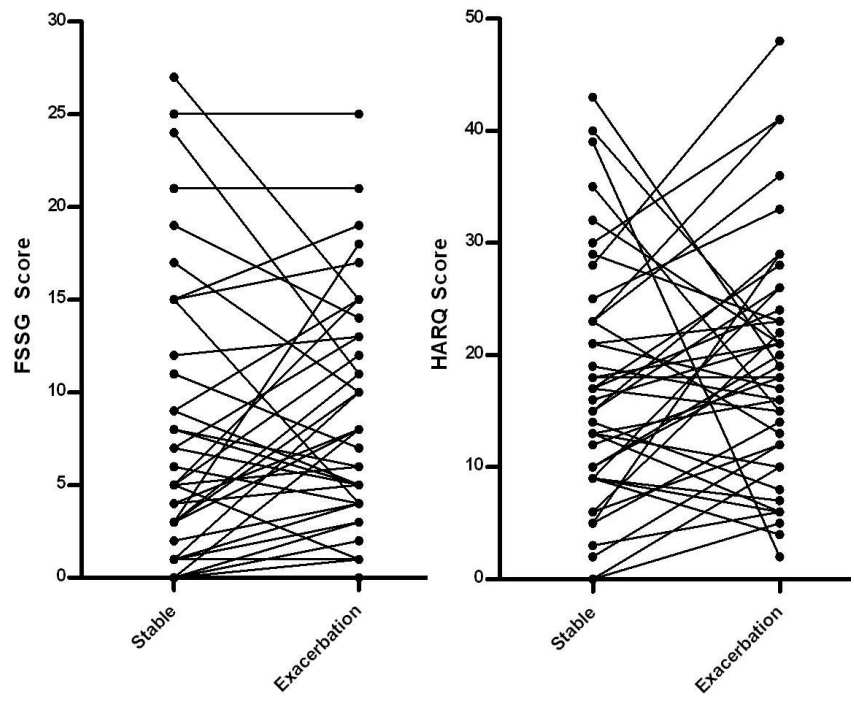

Abstract P214 Figure 1

\section{P215 LEFT VENTRICULAR HYPERTROPHY IN CHRONIC OBSTRUCTIVE PULMONARY DISEASE WITHOUT HYPOXAEMIA: THE ELEPHANT IN THE ROOM?}

doi:10.1136/thoraxjnl-2012-202678.276

WJ Anderson, BJ Lipworth, S Rekhraj, AD Struthers, J George. University of Dundee, Dundee, United Kingdom

Background Chronic obstructive pulmonary disease (COPD) is associated with significant cardiovascular mortality. Left ventricular hypertrophy $(\mathrm{LVH})$ is a pivotal cardiovascular risk factor. The prevalence of LVH in COPD is currently unknown.

Methods We performed a pilot study of 93 normoxaemic COPD patients and 34 controls. Patients underwent echocardiography to measure left ventricular (LV) dimensions; electrocardiography; 24-hour blood pressure (BP) recording; and serum B-type natriuretic peptide (BNP) levels, along with spirometry and oxygen saturations. Results COPD patients' oxygen saturations were normal at $96.5 \%$ (95\%CI: $96.1-97.0 \%)$, with a mean FEV1 of $70.0 \%$ predicted $(95 \%$ CI: $65.2-74.8 \%$ ). $30.1 \%$ of COPD patients met echocardiographic criteria for LVH based on LV mass index, with more LVH in females than males ( $43.2 \%$ vs. $21.4 \%$, p=0.02). LV mass index in COPD was $96.2 \mathrm{~g} / \mathrm{m}^{2}$ (95\%CI: $\left.90.1-102.7 \mathrm{~g} / \mathrm{m}^{2}\right)$ vs. controls $82.9 \mathrm{~g} / \mathrm{m}^{2}(95 \% \mathrm{CI}$ : $75.8-90.6 \mathrm{~g} / \mathrm{m}^{2}$ ), $\mathrm{p}=0.017$ (Figure 1). LV mass index remained high in COPD patients in the absence of hypertension history $\left(94.5 \mathrm{~g} / \mathrm{m}^{2} \mathrm{vs}\right.$. $\left.79.9 \mathrm{~g} / \mathrm{m}^{2}, \mathrm{p}=0.015\right)$ and with $24-\mathrm{hr}$ systolic $\mathrm{BP}<135 \mathrm{mmHg}(96.7 \mathrm{~g} /$ $\mathrm{m}^{2}$ vs. $\left.82.5 \mathrm{~g} / \mathrm{m}^{2}, \mathrm{p}=0.024\right)$. LV ejection fraction (mean $=63.4 \%$ ) and BNP $($ mean $=28.7 \mathrm{pg} / \mathrm{ml}$ ) were normal in COPD patients. Mean $24 \mathrm{hr}$ BP was normal in COPD patients at $125 / 72 \mathrm{mmHg}$. Electrocardiography was less sensitive for detecting LVH than echocardiography.

Conclusion LVH was present in a significant proportion of normotensive, normoxaemic COPD patients, especially in females, along with normal LV ejection fraction and BNP levels. Clinical trials are therefore indicated to evaluate treatments to regress $\mathrm{LVH}$ in patients with COPD.

\section{Figure 1}

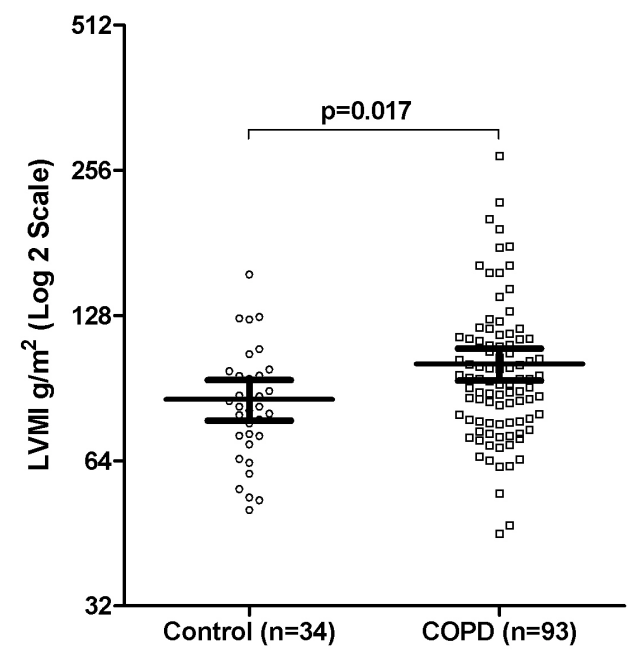

Left Ventricular Mass Index (LVMI) between groups. Presented as scatterplots of all data points with solid lines representing respective geometric means and $95 \% \mathrm{Cls}$. Means comparison with Student's T-test for unpaired samples (two-tailed). Significance set at $p<0.05$.

Abstract P215 Figure 1

\section{P216 IMPACT OF TACHYCARDIA AND NEW ONSET ATRIAL}

doi:10.1136/thoraxjnl-2012-202678.277

'PM Short, ${ }^{1} \mathrm{JD}$ Chalmers, ${ }^{2} \mathrm{AR}$ Akram, ${ }^{3} \mathrm{~A}$ Singanayagam, 'S Schembri, ${ }^{1} \mathrm{PA}$ Williamson. ${ }^{1}$ Ninewells Hospital, Dundee, United Kingdom; 'Royal Infirmary of Edinburgh, Edinburgh, United Kingdom; $3 /$ mperial College, London, United Kingdom

Introduction and Objectives Cardiac arrhythmias are regularly found in patients with COPD, with higher frequencies reported during exacerbations. We wished to examine the impact of tachycardia and new onset atrial fibrillation (AF) on long term outcome in patients hospitalised with a COPD exacerbation. 